\title{
CRENÇA TEÍsta: reflexividade e aderência
}

\author{
THEISTIC BELIEF: \\ reflexivity and adherence
}

\section{Daniel De Luca-Noronha * José Carlos Sant'Anna **}

\begin{abstract}
RESUMO
O objetivo do artigo é apresentar uma concepção de crença teísta que permita a articulação de dois aspectos: reflexividade e aderência. $\mathrm{O}$ primeiro aspecto consiste na ideia de que a crença teísta aparece como resultado de uma reflexão acerca de um determinado tipo de experiência. O segundo aspecto consiste no caráter evocativo e transformador da crença teísta. De acordo com algumas abordagens, entretanto, se a crença teísta tivesse um caráter reflexivo, ela não teria o tipo de aderência que lhe é própria. Esse argumento pressiona a concepção da crença teísta como crença básica, a saber, como uma atitude proposicional que constitui a experiência. No entanto, há ao menos uma circunstância relevante de formação de crença teísta, a experiência de vastidão, em que a experiência deve ser concebida como independente de crenças. Para essa circunstância, a crença teísta deve ser concebida como reflexiva. Nesse caso, cabe mostrar de que modo ela pode ser aderente. Tendo em vista o marco teórico integrativo da cognição ancorada, mostraremos que o caráter reflexivo da crença teísta não anula o seu caráter aderente.
\end{abstract}

Palavras-chave: Crença teísta. Experiência perceptiva. Cognição ancorada.

\begin{abstract}
The aim of this paper is to state a conception of theistic belief that takes into account two important aspects: reflectiveness and adherence. The first aspect involves the idea that theistic belief stems from reflection about a specific kind of experience. The second aspect consists in the evocative and transformative character of theistic belief. However, according to some lines of thought, if theistic belief had a reflective character, it would not have the kind of adherence that is its own. This argument leads to conceiving of theistic belief as a basic belief, i.e., as a propositional attitude that constitutes experience. In spite of this, we argue that there is at least one circumstance of theistic belief formation in which the relevant experience has to be conceived as belief-independent. This circumstance is the perceptual experience of vastness. With respect to this kind of experience, the theistic belief must be conceived as reflective belief. It remains for us to show how theistic beliefs can be adherent. Assuming the approach of grounded cognition, we argue that the reflective aspect of theistic belief does not cancel its adherent character.

Keywords: Theistic belief. Perceptual experience. Grounded cognition

\footnotetext{
* Doutor em Filosofia pela Universidade Federal de Minas Gerais. Atualmente é professor e pesquisador da Faculdade Jesuíta de Filosofia e Teologia (FAJE).E-mail: deluca.11@gmail.com

** Licenciado em Filosofia pela Faculdade Jesuíta de Filosofia e Teologia (FAJE) e mestrando em Filosofia pela mesma instituição. Trabalha com suporte técnico na plataforma OJS/SEER para os periódicos: Síntese, Perspectiva Teológica e Pensar. E-mail: santanna.carlos1@gmail.com
} 


\section{A ESPECIFICIDADE DA CRENÇA TEÍSTA}

O objetivo central desse artigo é apresentar uma concepção de crença teísta que possa articular dois de seus aspectos centrais: reflexividade e aderência. A abordagem será restrita a uma tentativa de descrever os mecanismos cognitivos e emocionais da crença teísta. Não se trata, portanto, de uma abordagem de cunho epistêmico. Com efeito, não é nosso objetivo adentrar as discussões acerca da justificação ou da verdade da crença teísta, mas sim, investigar os seus processos formadores. A concepção de crença teísta aqui utilizada envolve a crença em um Deus criador, que é onipotente e onisciente. Como se sabe, tal crença ganha expressão em religiões monoteístas, como o judaísmo, o cristianismo e o islamismo. Mas a nossa abordagem não depende de uma doutrina particular, tampouco dos modos específicos pelos quais a crença teísta é interpretada em cada uma dessas tradições religiosas. O que iremos afirmar aqui vale para o sujeito que adere a esse tipo de crença, independentemente de estar inserido em uma ou em outra tradição.

Tendo em vista essas considerações introdutórias, é conveniente para os nossos propósitos postular três características importantes da crença teísta, que conjuntamente mostram o seu traço aderente. A primeira é o caráter transformador. Tal como ocorre nos processos de conversão religiosa, a aquisição da crença teísta pode alterar profundamente a vida das pessoas. A segunda característica é o caráter memorável. A crença teísta tem, comumente, um alto grau de saliência na memória que se manifesta, inclusive, em imagens mentais. A terceira característica é o caráter evocativo. Em diversos momentos ao longo da vida, as pessoas evocam a crença teísta como uma tentativa de superar dificuldades ou desafios. Como podemos acomodar essas características em uma concepção geral de crença teísta? Há uma disputa na filosofia da religião acerca da natureza da crença teísta, a saber, ou bem como uma crença básica, ou bem como crença reflexiva. Antes de tomarmos posição sobre essa disputa, vejamos, a partir de uma abordagem neutra em relação a crenças, cada uma dessas concepções. 
Vamos iniciar com a concepção de crença básica. Para bem compreendermos esse tipo de crença, partiremos de uma concepção confiabilista, segundo a qual crenças são estados mentais que guiam o nosso comportamento no mundo. ${ }^{1}$ De acordo com essa concepção, crenças são estados intencionais que possuem valor adaptativo. As crenças são assim concebidas como parte do que explica o nosso comportamento no mundo físico. ${ }^{2}$

Um argumento central dessa posição é que os mecanismos produtores de crenças com função adaptativa são confiáveis. Um exemplo de um desses mecanismos é a percepção. Nossas capacidades perceptivas nos colocam em contato direto com o mundo. As crenças que são causadas pelos mecanismos perceptivos apropriados permitem que nossas ações estejam ajustadas ao ambiente. É importante notar que o mecanismo produtor da crença em questão, para que possa exercer sua função adaptativa, não precisa ser conhecido pelo agente. $\mathrm{O}$ que garante a confiabilidade desse processo não depende de um acesso reflexivo, em primeira pessoa, por parte do agente. Essa confiabilidade depende, isto sim, de uma história natural ou evolutiva de sucesso da performance do mecanismo frente às pressões adaptativas.

Essas crenças causadas diretamente pelos impactos do mundo em nossas capacidades perceptivas são denominadas "crenças básicas". Elas são compreendidas como básicas precisamente porque o processo de sua aquisição é passivo. A aquisição não depende do assentimento ou da vontade do agente. Ademais, essas crenças não são adquiridas mediante inferências baseadas em outras crenças. São, antes, causadas diretamente por mecanismos perceptivos e constituem parte do complexo causal que resulta em comportamentos no mundo. Tal passividade pode ser entendida mediante a consideração de que crenças bá sicas têm papel causal no comportamento intencional mesmo sem figurarem em um processo explícito de deliberação prática (McDOWELL, 1994).

Seguindo um exemplo de John McDowell (1998), considere-se que um agente pode alterar o curso da sua ação de maneira irrefletida por causa da

${ }^{1}$ Sobre o confiabilismo, Goldman (1976).

${ }^{2}$ Sobre isso, VER, o princípio de Ramsey (1978) que conecta verdade da crença ao sucesso da ação.

INTERAÇÕES, Belo Horizonte, Brasil,v.13, n. 24, p. 503-525, Ago./Dez. 2018 ISSN $1983-2478$ 
percepção de uma placa que aponta para uma direção inesperada. 3 Se em um momento posterior à ação lhe for pedido alguma razão que justifique a mudança de rumo, ele é capaz de oferecê-la. Ele alega que o motivo consiste em uma placa que apontava na direção contrária ao rumo previsto. Daí podemos dizer que ele formou a crença de que havia uma placa apontando para uma dada direção. Mas a sua crença adquirida pela percepção visual da placa, no decorrer da ação, não figurou como uma premissa de um raciocínio prático. A aquisição dessa crença não envolveu, portanto, o emprego de capacidades reflexivas.

Temos, assim, uma concepção geral de crenças básicas. Vejamos agora uma concepção de crenças reflexivas. Para isso, vamos considerar uma variação do exemplo acima: diante da percepção da placa, o agente interrompe a sua ação e se pergunta se vale a pena alterar o rumo previsto de sua ação. Como resposta, o agente adquire a crença de que ele deve seguir no rumo previsto. Essa crença já não possui um caráter básico. Ela resulta de um processo inferencial explícito. Esse processo tem como premissas o conteúdo da experiência - ou mesmo outras crenças.

A aquisição dessa crença não ocorre de forma passiva. Sua aquisição se deve ao emprego ativo de capacidades cognitivas pelas quais realizamos inferências. Ademais, esse tipo de crença está, por assim dizer, indiretamente relacionada à experiência. Ou seja, ela é menos constrangida pelos impactos do mundo do que as crenças básicas, que são adquiridas de forma passiva. As crenças menos constrangidas pelo mundo figuram nas racionalizações da experiência, ou mesmo na racionalização de outras crenças. Tais crenças são, nesse sentido amplo, reflexivas.

Uma segunda variação do exemplo acima pode deixar esse ponto ainda mais claro: considere-se que o agente está em uma situação perceptiva anormal. Ao se deparar com a percepção de algo que apenas lhe parece uma placa, ele adquire a crença de que sua própria experiência é ilusória. Aqui temos uma tomada de posição acerca da própria experiência. O agente recusa o conteúdo em tela,

3 É importante notar que, como mostram os casos de blindsight, sequer a placa precisa estar no foco da atenção do agente para que ele reaja, ou seja responsivo, a ela. Sobre o fenômeno de blindsight, (LEOPOLD, 2012). 
tomando-o como ilusório. Mais uma vez, a crença de que se está perceptivamente iludido é resultado de um processo inferencial, que depende da atividade de capacidades cognitivas. Ademais a aquisição de tal crença depende da posse de uma psicologia de senso comum (folk psychology), vale dizer, de uma teoria comum da mente na qual o conceito de ilusão perceptiva, conectado a outros conceitos psicológicos, adquire significado. A posse do conceito de ilusão perceptiva, que se coloca em operação no juízo acerca dessa experiência, requer outros tantos elementos além de uma experiência irregular do mundo.

Tendo em vista a diferença entre esses dois tipos de crença, em qual deles podemos situar a crença teísta? Ora, numa primeira aproximação, podemos dizer que a crença teísta possui caráter reflexivo. Parece razoável afirmar que a crença teísta envolve uma interpretação do conteúdo da experiência perceptual. O conteúdo dessa experiência, além de outras crenças de fundo, coloca-se como premissa de um procedimento inferencial, cuja conclusão é uma determinada interpretação teísta da experiência. Por exemplo, diante de uma determinada experiência perceptual, o agente infere ou interpreta um dado fenômeno como criação de Deus, ou como manifestação de algum outro tipo de envolvimento divino. Nessa perspectiva, a crença teísta é, ela mesma, um resultado desse processo inferencial. O impacto do mundo opera aqui de forma muito indireta. Portanto, tal crença não pode ser considerada como básica.

Destacam-se dois problemas que se colocam na compreensão mesma da crença teísta como básica. O primeiro é o risco de se inflacionar o conteúdo da percepção. Parece de algum modo enganoso afirmar que podemos ver objetos que violam o comportamento daqueles que pertencem a categorias às quais nosso aparato sensorial é sensível. Não menos duvidosa é a afirmação de que podemos ver outras mentes, ou qualquer fenômeno que não tenha poderes causais diante do nosso aparato sensorial. A respeito de outras mentes, por exemplo, parece mais plausível afirmar que estados mentais, como crenças, desejos e intenções, são inobserváveis. Na compreensão de outras mentes, o que se encontra disponível à percepção do intérprete é o comportamento do outro. A partir dessa percepção, o intérprete infere os estados mentais que podem explicar esse comportamento. Mais 
uma vez, afirmar que vemos outras mentes parece ser equivocado. Nessa linha argumentativa, a percepção de Deus enquanto um ser sobrenatural cairia no mesmo problema.

O segundo problema consiste na neutralização do papel central das crenças básicas em episódios de coordenação de ações ${ }^{4}$. Considere-se a circunstância em que um teísta e um ateísta observam um mesmo objeto e coordenam suas ações em torno dele. Para o teísta, o objeto em questão é uma manifestação divina; já, para o ateísta, um objeto cuja existência contingente não depende de um Deus criador. Nesse nível superior, portanto, suas crenças possuem conteúdos semânticos diferentes. $\mathrm{O}$ que pode explicar essa diferença são as diferentes crenças recrutadas no processo de compreender a experiência.

Mas essa diferença não elimina o fato de que, em algum nível mais básico, eles compartilham de uma mesma crença básica. Essa crença básica compartilhada é diretamente causada pela experiência perceptiva de ambos com o mesmo objeto. O compartilhamento dessa crença permite, por exemplo, que eles carreguem conjuntamente esse objeto, que o mantenham no foco da atenção mútua em um episódio conversacional, ou ainda que o reconheçam como o mesmo objeto em diferentes circunstâncias. Essas habilidades dependem de crenças básicas. Por certo, eles podem interpretar as suas respectivas experiências perceptivas com o objeto valendo-se de suas crenças reflexivas. Mas essa atividade reflexiva não chega modificar essas habilidades. É justamente nesse nível mínimo de compartilhamento da experiência perceptiva que podemos encontrar as crenças básicas. À primeira vista, portanto, o movimento de tomar a crença teísta como básica forçaria-nos a situá-la nesse nível mínimo compartilhado. Entretanto, dado que a crença teísta não é tão fortemente compartilhada quanto crenças empíricas, esse movimento não parece razoável.

Em suma, essas considerações iniciais ensejam a compreensão da crença teísta como uma crença reflexiva. Nosso problema será, então, esclarecer que a concepção reflexiva da crença teísta permite levar em conta a sua aderência. Antes

4 A esse respeito, Donald Davidson propôs o argumento da triangulação. Cf. Davidson (1997). 
disso, contudo, é importante analisar uma tentativa interessante de se compreender a crença teísta como básica.

\section{A CRENÇA TEÍSTA COMO CRENÇA BÁSICA?}

No tópico anterior, discutimos alguns aspectos que tornam a crença teísta aderente. Além disso, apresentamos argumentos que nos levam a compreender a crença teísta como reflexiva. No entanto, alguns filósofos e cientistas cognitivos entendem que esses aspectos devem levar a compreensão da crença teísta como crença básica. Isso porque as crenças teístas costumam ter um impacto profundo na vida das pessoas. Podemos observar esse fato não apenas lendo relatos notáveis de conversão religiosa, mas voltando nossa atenção para situações comuns. Não são raras as situações de mudança profunda de hábitos pelas quais as pessoas passam a partir da aquisição desse tipo de crença. Ademais, há um conjunto bem delimitado de situações nas quais a crença teísta é evocada, mesmo por parte de pessoas que não se habituaram a se engajar em contextos de prática religiosa. Não menos importante é observar que a crença teísta continua fortemente disseminada entre a população mundial da atualidade, mesmo diante da penetração da explicação científica acerca de diversos fenômenos no senso comum.

A tentativa de explicar esses indícios pode nos levar à tese de que seres humanos possuem uma disposição natural em produzir esse tipo de crença (McCAULEY, 2011). Ou pelo menos à tese segundo a qual a sua aquisição está ao lado da aquisição de outras tantas crenças. Nessa perspectiva, a crença teísta estaria ao lado da crença em objetos materiais ou da crença em outras mentes. Essas são crenças com as quais estamos fortemente comprometidos, que começam a ser formadas desde as primeiras etapas da ontogênese. Justamente esse fato que pode explicar o caráter aderente da crença teísta, em particular, o motivo pelo qual ela é tão resistente diante de objeções e dúvidas. Observe-se também que a aderência da crença teísta parece requerer algum tipo de passividade no processo de sua aquisição. Assim como ocorre com respeito à crença em objetos materiais, a manutenção da crença teísta pode não estar sob o controle de nossas capacidades 
reflexivas. Enfim, é provável que o esforço cognitivo associado a essas capacidades, se houvesse, tornaria os crentes teístas bem mais céticos do que de fato são em relação à sua própria crença. Há, portanto, problemas importantes que se colocam para a estratégia de assimilar a crença teísta como crença reflexiva (voltaremos a esse ponto).

Façamos uma breve retomada do que vimos até aqui. Começamos propondo uma diferença entre as crenças básicas e crenças reflexivas. Ao que parece, temos razões prima facie para compreender a crença teísta como reflexiva. No entanto, ao desdobrar os aspectos constitutivos da crença teísta, observamos um limite aparente acerca da sua compreensão nos moldes reflexivos. Essa constatação nos exige avaliar uma forma mais elaborada de assimilar a crença teísta como básica. Tal estratégia pode ser encontrada em Alvin Plantinga.

Como se sabe, a abordagem de Plantinga (2000) acerca da crença teísta tem motivações epistemológicas. Sua preocupação é defender a racionalidade da crença teísta. De acordo com Plantinga, trata-se de uma crença que possui condições de verdade e de justificação do mesmo modo que crenças empíricas. Mas é interessante observar que o percurso de Plantinga inclui tanto argumentos de ordem epistemológica, quanto uma descrição dos mecanismos cognitivos produtores da crença teísta.5 Plantinga baseia-se largamente em tais mecanismos para mostrar o modo pelo qual crenças teístas podem ser justificadas ou, tal como ele pretende, garantidas ou avalizadas (warranted). ${ }^{6}$ Ele afirma que a racionalidade da crença religiosa depende do funcionamento adequado dos mecanismos cognitivos operando em contextos apropriados. O funcionamento adequado de determinados mecanismos conduz à verdade das crenças teístas, de mesmo modo que o funcionamento adequado de outros mecanismos perceptuais conduz à verdade das crenças empíricas. Essa posição de Plantinga o alinha ao externismo sobre justificação. Esse passo, por sua vez, o permite afirmar que crenças teístas são tão básicas como, por exemplo, crenças perceptuais. Assim

5 Interessante notar que Plantinga baseia-se na noção de função própria, uma noção largamente utilizada por filósofos de inspiração naturalista, como Millikan (1984) e Dretske (1999).

${ }^{6}$ Com o conceito de "warranted", Plantinga quer se afastar de uma posição internista e, sendo assim, mostrar que o agente não precisa refletir acerca do modo como a crença foi adquirida para estar justificado. 
como essas últimas, são crenças que não dependem do emprego de capacidades inferenciais ou reflexivas por parte dos agentes. Tais crenças resultam de mecanismos cognitivos que são ativados em contextos apropriados independentemente da vontade do agente.

Mas qual desses mecanismos teria a função de produzir crenças teístas? Para Plantinga, tal disposição pode ser compreendida mediante o conceito de sensus divinitatis postulado, com algumas diferenças, por Calvino e Tomás de Aquino. A ideia é que temos uma disposição cognitiva sensível à manifestação divina, que opera independentemente de processos deliberativos por parte do agente. Assim o sensus divinitatis seria um mecanismo gerador de uma crença teísta de caráter básico.7

Quais são os contextos aos quais o sensus divinitatis é sensível? Plantinga afirma que, dada a onipresença divina, há diferentes contextos que podem induzir a atividade do sensus divinitatis. Os exemplos propostos por Plantinga vão desde a experiência de vastidão, como a percepção de uma paisagem de grande magnitude, até casos de sofrimento, dor e perda (PLANTINGA, 2000, p. 158). A essa variação contextual corresponde a variação de capacidades associadas ao sensus divinitatis. Além da percepção, a memória e os sentimentos também estão associadas a esse "sentido de Deus." Essas diferentes capacidades explicariam o fato de que nem sempre a crença teísta envolve imagens. Às vezes pode envolver estritamente um sentimento da presença de Deus, sem nenhuma fenomenologia específica.

A despeito dessa ampla variação contextual, existe algo que, segundo Plantinga, se faz presente em todas as operações do sensus divinitatis. Trata-se do que ele chama de "experiência doxástica". Plantinga define a experiência doxástica como uma experiência que

\footnotetext{
7 Plantinga esclarece a ideia do sensus divinitatis do seguinte modo: “(...) the basic idea, I think, is that there is a kind of faculty or a cognitive mechanism, what Calvin calls a sensus divinitatis or sense of divinity, which in a wide variety of circumstances produces in us beliefs about God. These circumstances, we might say, trigger the disposition to form the beliefs in question; they form the occasion on which those beliefs arise. Under these circumstances, we develop or form theistic beliefs-or, rather, these beliefs are formed in us; in the ty pical case we don't consciously choose to have those beliefs. Instead, we find ourselves with them, just as we find ourselves with perceptual and memory beliefs. (You don't and can't simply decide to have this belief, thereby acquiring it.)" (PLANTINGA, 2000, p. 144).
} 
one has when entertaining any proposition one believes. Entertaining, for instance, the proposition that $3+2=5$ or that Mount Everest is higher than Mount Blanc feels different from entertaining one you think is clearly false $-3+2$ $=6$, for example, or Mount Blanc is higher than Mount Everest. The first two feel natural, right, acceptable; the second two feel objectionable, wrong, eminently rejectable. As I say, this experience is always connected with operations of the sensus divinitatis, because always connected with the formation or sustenance of any belief. So all of these varieties of experience can be found in the operation of the sensus divinitatis; doxastic experience accompanies any beliefs formed by its operation, as it does the formation of any other belief (PLANTINGA, 2000, p. 1523).

Com o conceito de experiência doxástica, acreditamos que Plantinga deseja unir duas coisas: em primeiro lugar, a ideia de que o sensus divinitatis envolve estados doxásticos, ou seja, estados dotados de conteúdo proposicional. Assim, trata-se de um mecanismo produtor de atitudes proposicionais como crenças. Ora, Plantinga endossa a concepção tradicional de que crenças são estados cognitivos cujo conteúdo é especificado pela partícula "que" (that-clause), que se coloca tipicamente no contexto de atribuição de tais estados. Quem tem uma crença acredita que as coisas são de tal e tal modo. Trata-se de um conteúdo articulado proposicionalmente. Nessa perspectiva, a crença é uma atitude proposicional que nos abre para uma dada disposição do mundo.

Em segundo lugar, a ideia de que se trata de um mecanismo associado a experiências com um conteúdo proposicional que parece verdadeiro. Mediante esse segundo aspecto, Plantinga deseja contemplar o caráter direto ou não inferencial da formação da crença teísta. Mais uma vez, ocorre uma experiência doxástica independentemente da vontade do agente. Ocorre uma experiência passiva que o leva como que forçosamente à crença teísta.

A questão que se coloca é se esse conceito de Plantinga pode acomodar a aderência da crença teísta, sem recorrer à noção de reflexividade. Ora, um ganho da posição de Plantinga consiste, por certo, no seu movimento de conectar a crença teísta a um mecanismo cognitivo básico que opera aquém da deliberação do agente. Este pode ser um passo para se esclarecer a aderência dessa crença. No entanto, defendemos que um dos problemas na abordagem de Plantinga incide sobre a sua 
abordagem de experiência. Note-se que a ideia de experiência doxástica remete a uma experiência cognitiva, vale dizer, uma experiência que embute a crença teísta. Mas existe ao menos uma circunstância de operação do sensus divinitatis, talvez a mais notável, em que a experiência perceptiva não pode ser concebida como cognitiva. Isso porque essa experiência não embute crenças, mesmo crenças básicas. Trata-se da experiência perceptiva com o ambiente vasto, que se nos apresenta com grande magnitude. Ademais, como ainda veremos, é justamente o fato de não se tratar de uma experiência cognitiva que explica a sua aderência. Vejamos um modo plausível de compreender a experiência de vastidão.

\section{O CONTEÚDO NÃO-CONCEITUAL DA EXPERIÊNCIA DE VASTIDÃo}

Vimos que a estratégia de Plantinga de assimilar a crença teísta como crença básica depende de um certo tipo de experiência doxástica direcionada a um objeto articulado proposicionalmente. Essa noção robusta de experiência requer o envolvimento de crenças. Se houvesse uma noção de experiência independente de crenças, Plantinga estaria comprometido com uma concepção reflexiva da crença teísta - (um ponto do qual deseja, manifestamente, afastar-se). Com efeito, tal crença resultaria de um processo inferencial, que teria início em uma experiência cujo conteúdo seria neutro em relação ao teísmo. O exemplo já visto ilustra bem esse ponto: ao observar um dado fenômeno físico, o agente infere a presença de Deus. Nesse quadro, a crença teísta consistiria em uma interpretação de uma experiência que se nos apresenta com um conteúdo ordinário. Plantinga entende que essa concepção enfraquece a crença teísta.

No entanto, pretendemos fazer justiça a um determinado tipo de experiência perceptual à qual o sensus divinitatis é sensível. Trata-se da experiência perceptiva da vastidão. Nesse caso, existem argumentos fortes o suficiente para concebermos a experiência independentemente do seu envolvimento com crenças, quer sejam reflexivas ou básicas. Veremos abaixo que, no caso da vastidão, a experiência perceptual relevante possui conteúdo não-conceitual. 
Suponhamos que estamos fazendo uma trilha no alto das montanhas em Annaberg, na Baixa Áustria. Em um determinado momento da trilha, no ponto mais alto da montanha, paramos e olhamos a paisagem daquela perspectiva. Perceberemos o verde das árvores, a coloração das flores, o posicionamento das nuvens, com o pico da montanha tocando-as, e outros tantos aspectos. Nossa percepção, portanto, será bombardeada com inúmeras informações desse contexto e se formos questionados sobre o que estamos vendo no alto da montanha discorreremos facilmente sobre os objetos da nossa percepção visual.

Provavelmente diremos frases do tipo: "vejo que as árvores apresentam variados tons de verde", "vejo que as flores colorem o campo" e "vejo que a montanha atravessa as nuvens", dentre outras. Esse modo de expressar sugere que tivemos a atitude proposicional de ver, o que é indicado claramente pela partícula "que" das frases citadas. Essa abordagem pode nos levar a propor que o conteúdo das nossas percepções, ou as informações que recebemos pela percepção, são informações estruturadas de maneira proposicional. Justamente esse tipo de abordagem que leva a assimilação da experiência perceptiva como crença básica. Mas essa é exatamente a questão colocada para nós: entender a natureza das informações que nos são entregues pela percepção. Ou, dito de outra forma: saber qual é o formato do conteúdo da experiência perceptual, se são proposicionais ou não.

Essas experiências perceptuais normalmente são consideradas em termos conceituais, i.e., seu conteúdo é o conteúdo de atitudes proposicionais como crenças básicas que, por sua vez, pressupõem a utilização de termos conceituais como componentes. A experiência visual descrita acima foi expressa utilizando termos como "nuvem", "árvore" e "flor", ou seja, parece que essa percepção só poderia ser do modo que foi porque pressupunha que possuíamos os conceitos de NUVEM, ÁRVORE, e FLOR. Assim, a maneira mais intuitiva é pensar que toda a nossa experiência perceptiva é envolvida em conceitos justamente pelo fato de poder-se expressá-la através de proposições, cujos componentes são conceitos de objetos reconhecidos como tais. Enfim, esse modo de pensar nos leva a conceber experiências como crenças básicas. 
No entanto, há vários filósofos que discordam dessa tese conceitualista, assumindo que não é todo o conteúdo da percepção que está envolvido em conceitos. Essa posição é conhecida como não-conceitualismo e foi formulada primeiramente por Gareth Evans, em sua obra The Varieties of Reference (1982). O argumento principal é que nossas capacidades discriminativas são mais amplas que as nossas capacidades conceituais. Isso conduz à noção de que nosso repertório conceitual não exaure inteiramente todo o conteúdo que nos é entregue na percepção. O próprio Evans afirmou que há um estágio mais primitivo do que aquele em que se encontram as atitudes proposicionais, chamado por ele de "estado informacional". Não são acomodadas proposições nesse estado informacional, e essa é a característica fundamental desse estado: ele é independente de crença. Um estado mental de crença, mesmo básica, seria um estado cognitivo. Isso não significa, entretanto, que não há nenhum nível representacional no estado informacional ${ }^{8}$.

Voltemos para o exemplo da montanha de Annaberg. Um nãoconceitualista dirá que não seremos capazes de discriminar conceitualmente todas as informações acolhidas na percepção no momento em que visualizamos a paisagem porque há uma fineza na percepção que não ocorre em nosso repertório conceitual. Enquanto observo as árvores, por exemplo, irei discriminar perceptivamente várias tonalidades de verde. No entanto não terei termos gerais para discriminar conceitualmente cada uma delas. Isso é o que foi dito por Evans na famosa passagem: "Do we really understand the proposal that we have as many color concepts as there are shades of color that we can sensibly discriminate?" (Evans 1982, p. 229). Evans utiliza o exemplo da percepção visual, mas obviamente isso vale como representante para todos os estados perceptivos ${ }^{9}$.

8 O exemplo de uma percepção ilusória também pode evidenciar que essas experiências são portadoras de um conteúdo não-conceitual por representar um determinado estado de coisas contraditório ou impossível, e que uma crença completamente formulada ainda seria um estado cognitivo bastante avançado e pertencente a um sistema normativo. Sobre isso, Evans (1982, p. 123).

9 O conteúdo da experiência perceptual é caracterizado como sendo não -conceitual tanto no nível pessoal quanto no nível subpessoal, e nesse estado informacional entram em operação as informações reunidas pela percepção, testemunho e memória. Essas distinções não serão importantes para nossa proposta. Sobre essetema, Bermúdez (2007) e Evans (1982, p. 122 -129). 
Essa diferença de refinamento entre as discriminações perceptivas e capacidades conceituais é o motivo pelo qual Evans compreende o conteúdo da percepção como estruturado de forma não-conceitual e, ipso facto, não proposicional. Esse conteúdo é conceitualizado somente quando nos movemos da experiência perceptual para o âmbito do juízo, como exemplificado anteriormente ${ }^{10}$.

Assim é pouco plausível que nossa experiência perceptual do mundo, especialmente em situações típicas de vastidão perceptiva, como a do nosso exemplo da visão do alto da montanha de Annaberg, seja inteiramente exaurida pelo nosso repertório conceitual. Ao contrário, o que ocorre, antes, é a recepção de um conteúdo que é não-conceitual em função da riqueza das informações entregues à percepção.

Como no exemplo da visão panorâmica de uma montanha em Annaberg, o conceito de vastidão pode dar a entender que essa qualificação poderia ser usada apenas em grandes ambientes físicos. No entanto ela ocorre quando é apresentado ao sujeito qualquer objeto que impressione fortemente a sua percepção, seja pelo tamanho, pelo nível de detalhamento ou de repetição harmoniosa de padrões. Logo, um contexto de vastidão ocorre sempre que as informações capturadas perceptivamente desafiam o quadro de referência em que um sujeito está acostumado, gerando uma violação de expectativa através de um conteúdo nãoconceitual. Esse conteúdo não é assimilado, mas acomodado, segundo a abordagem cognitiva de Piaget (PIAGET; INHELDER, 1966). Um caso de assimilação ocorre quando envolve interpretação das informações de modo que sejam adicionadas em esquemas conceituais já existentes ao sujeito. O contrário ocorre com a acomodação, quando a atenção se volta especificamente para as informações que se desviam dos esquemas conceituais que o sujeito possui, pressionando a atualização ou criação de novos esquemas para que aquela informação seja armazenada de um

10 Há também outro famoso trecho de Evans sobre a passagem do âmbito da percepção para o âmbito do juízo: "The informational states which a subject acquires through perception are non conceptual, or non-conceptualized. Judgements based upon such states necessarily involve conceptualization: in moving from a perceptual experience to a judgement about the world (usually expressiblein some verbal form), one will be ex ercising basic conceptual skill." (Evans 1982, p. 227). 
modo minimamente coerente em seu sistema de crenças. Assim, o caso de vastidão perceptual é um caso propício para que haja acomodação de conteúdo nãoconceitual.

Estudos recentes em psicologia cognitiva têm trazido à tona a relação entre o que aqui denominamos conteúdo não-conceitual da experiência e emoções. Segundo Keltner e colaboradores (SHIOTA, et al. 2007), a emoção de awe (sentimento de respeito, admiração e de ser muito impressionado perceptivamente) é provocada sempre que há essas duas características: contexto de vastidão perceptual e necessidade de acomodação. E um contexto muito propício que manifesta essa emoção é um cenário panorâmico de beleza natural, como o da montanha de Annaberg. No artigo em tela, Keltner e colaboradores procuraram criar um ambiente propício para a manifestação de awe. Para isso eles submeteram várias pessoas a situações de vastidão perceptual, nas quais elas estariam propensas a manifestar awe em função dos estímulos recebidos pela percepção. O resultado foi que essas pessoas tiveram pensamentos mais recorrentes de pequenez, da presença de algo maior que elas, de despreocupação com as tarefas ordinárias e de conexão com o mundo. Também perceberam que emoções de admiração, amor, contentamento e êxtase eram bem mais recorrentes que as emoções de orgulho, medo e excitação. Por fim, isso aponta ainda mais claramente para a tese de que as emoções e pensamentos recorrentes em estados de awe são provenientes de uma quebra de expectativa em função dos estímulos perceptivamente ricos. Essa quebra de expectativa, por sua vez, propicia a acomodação de um conteúdo não-conceitual.

Descrevemos uma situação à qual o sensus divinitatis é sensível, a saber, a percepção de vastidão. No entanto, o tipo de experiência perceptiva diante dessa situação tem caráter não-conceitual. Por esse motivo, não se trata de uma “experiência doxástica” de tipo conceitual, que poderia envolver crença. Segue-se que, ao menos nesse caso, a crença teísta não pode ser compreendida como uma crença básica. A crença teísta se nos apresenta aqui como uma tomada de posição, ou como uma tentativa de acomodar uma experiência de caráter não conceitual. Trata-se, nesse sentido preciso, de uma crença reflexiva. 
Em suma, além das razões colocadas no tópico anterior, a experiência de vastidão, de caráter não-conceitual, pressiona a compreensão da crença teísta como crença reflexiva. Nesse caso, devemos mostrar que o caráter reflexivo da crença teísta não é incompatível com os aspectos que a tornam aderente. No tópico que se segue, sugerimos um quadro teórico em que esse caráter reflexivo da crença teísta pode estar associado à sua aderência. Trata-se da abordagem da cognição ancorada.

\section{EXPERIÊNCIA DE VASTIDÃO E CRENÇA REFLEXIVA}

Vimos um caso em que a crença teísta está direcionada a uma experiência perceptiva de vastidão. Nessa situação, a experiência não é assimilada no repertório conceitual do agente. Por esse motivo, trata-se de uma experiência que requer acomodação. Um modo de acomodar o seu conteúdo ocorre mediante a crença em uma manifestação de onipotência divina. Noutros termos, a crença teísta é empregada na tentativa de racionalizar essa experiência de caráter não-conceitual.

No entanto, pode aparecer um problema para essa defesa do caráter reflexivo da crença religiosa. No tópico acima afirmamos que o impacto emocional da experiência de vastidão decorre de seu caráter não-conceitual. No entanto, a crença reflexiva direcionada a essa experiência possui conteúdo conceitual, além de envolver capacidades cognitivas de alto nível. Essa consideração pode forçar a tese de que a crença teísta, compreendida em termos reflexivos, seja concebida como emocionalmente neutra. E o problema é tanto maior na medida em que, tendo a experiência um conteúdo mais fino do que o conteúdo conceitual, ele não parece passível de ser inteiramente armazenado na memória, ao menos de modo que esteja disponível para uma tarefa de reconhecimento. Nessa linha, a aderência, circunscrita à riqueza fenomenológica da experiência e às emoções pertinentes, não seria transferida para a crença. Em suma, se a crença teísta fosse reflexiva, ela não seria aderente.

O que pode sustentar essa objeção é a ideia de que capacidades cognitivas têm autonomia em relação a capacidades experienciais. Uma posição teórica que 
pode levantar esse tipo objeção é o chamado cognitivismo clássico. O cognitivismo é um movimento teórico amplo, com ramificações em diversas áreas do conhecimento, como ciência da computação, psicologia, linguística, filosofia entre outras. Nosso foco nessa breve exposição do cognitivismo incide, basicamente, sobre a concepção geral da mente que este propõe ou, em alguns casos, simplesmente pressupõe: trata-se da ideia de que processos cognitivos são processos de manipulação de símbolos (SHAPIRO, 2011). São processos que se encontram em analogia com os computadores, de modo a podermos falar de um modelo computacional da mente. A mente é concebida como um computador cujas partes armazenam, transmitem e copiam informações pertinentes para o modo de vida das espécies.

De acordo com o cognitivismo, os processos cognitivos são de ordem superior e estão confinados dentro dos limites intracranianos. Esses processos internos seriam autônomos no seguinte sentido: dizem-nos tudo o que há de relevante acerca da cognição humana. A analogia com os computadores é esclarecedora aqui: como ocorre com os computadores, o que se encontra na periferia do sistema não afeta, no essencial, o processamento central de informação. ${ }^{11}$ A ideia de que o processamento cognitivo envolve manipulação de símbolos segundo determinadas regras sugere que o conteúdo conceitual é de tipo amodal. Vale dizer, trata-se de um conteúdo que não é modulado por capacidades mais básicas do que as capacidades cognitivas, como as capacidades sensóriomotoras e afetivas. Dentro desse quadro teórico, o conceito DEUS mobilizado no sistema cognitivo perderia o viés afetivo ou emocional da experiência perceptiva de vastidão. Mais uma vez, dentro dessa posição não é claro como a crença teísta, enquanto figura em tal sistema cognitivo, pode ter caráter aderente.

À luz dessas considerações, postular a crença teísta como reflexiva seria como postular um epifenômeno sem o impacto transformador na vida dos agentes. Ou, no mínimo, uma crença menos aderente do que, como temos visto, a crença

\footnotetext{
${ }^{11}$ Shapiro fornece alguns elementos importantes dessa analogia: "Who is typing on the keyboard, the truth of what he or she is ty ping, and what this person does with the resulting outputs simply makes no difference to how the program works or to how one should go about describing how the program works.” (2011, p. 26)
} 
teísta parece ser. Em termos práticos, a mera evocação de uma crença teísta, em uma situação em que o agente não tem uma experiência perceptiva relevante como de vastidão, não o traria alívio, gratidão, entre outras emoções. Assim pode parecer que esse impacto transformador apareceria somente em um quadro teórico no qual a experiência de vastidão já embute crenças. Entretanto, já sabemos os problemas associados ao movimento de compreender a experiência de vastidão como crença. Cabe-nos, por conseguinte, mostrar como a crença reflexiva pode ter aderência nesse caso específico.

Nossa questão repousa naquilo que anunciamos no tópico anterior, a saber: a acomodação cognitiva de um conteúdo não conceitual dotado de forte tonalidade emocional. Notemos, logo de saída, que a transição do conteúdo da experiência para o conteúdo da crença, ou a passagem de um estado informacional para um estado cognitivo, envolve perda fenomenológica. ${ }^{12}$ Mas daí não se segue que 0 processo de conceituar o conteúdo da experiência seja imune aos aspectos constitutivos da experiência. O que pode fundamentar esse ponto é a tese de que os processos cognitivos (reflexivos) e experienciais não estão isolados. Podemos esclarecer essa tese a partir do quadro conceitual de teorias integrativas da mente como, em particular, a teoria da cognição ancorada (grounded cognition), proposta por Lawrence Barsalou e colaboradores (BARSALOU, 2008).13 Essas teorias surgem após o cognitivismo clássico e são motivadas, em alguma medida, por uma tentativa de superar os seus problemas.

De acordo com Barsalou, as capacidades cognitivas, mesmo de alto nível, estão ancoradas em capacidades sensoriais, afetivas e motoras. Isso significa que o conteúdo conceitual que é processado pelas estruturas cognitivas não é de um tipo amodal. Ou seja, não se trata de um conteúdo que se colocaria para além do modo específico pelo qual é processado por essas capacidades sensório-motoras e

\footnotetext{
$12 \mathrm{~A}$ ideia chave é que essa perda é essencial para que os conteúdos possam ser armazenados na memória. Sobre a passagem do conteúdo da experiência para o conteúdo cognitivo, Dretske (1981) e Evans (1982).

13 A teoria da cognição ancorada pode ser compreendida como uma te oria integrada porque leva em conta aspectos essenciais do cognitivismo (como o conceito de simulação), como também da cognição corporificada (como o incorporamento de capacidades cognitivas).
} 
afetivas. ${ }^{14}$ Pelo contrário, mesmo o processamento cognitivo abstrato é modulado por tais capacidades. Vejamos, segundo Barsalou, como ocorre o processo de conceituação do conteúdo da experiência.

A experiência recorrente com instâncias pertencentes a um mesmo tipo de fenômeno dispara a atividade de diferentes subsistemas neuronais. As informações advindas de diferentes canais sensoriais, que ativam esses subsistemas, são armazenadas na memória de longo prazo. Tais informações, por sua vez, são recrutadas e empregadas por esses subsistemas a cada novo encontro com o fenômeno em questão. O padrão geral de ativação desses diferentes subsistemas neuronais torna o fenômeno disponível para diferentes tipos de interação com o agente. Barsalou e colaboradores descrevem essa ativação dos subsistemas como simulação. Os processos de simulação podem ser de baixo ou de alto nível. No primeiro caso, por exemplo, a ativação da amígdala envolve a simulação de reações afetivas, a ativação do sistema motor envolve a simulação de tipos de ação em relação ao fenômeno, a ativação do sistema visual envolve representações pertinentes e assim por diante. No segundo caso, simulações constituem o domínio inferencial, por exemplo, na produção de contrafactuais e de cenários preditivos. É importante notar que os processos simulativos de baixo nível estão em conexão com os processos simulativos de alto nível. Isso ocorre nos casos em que esse conteúdo no nível sensório-motor e afetivo é recrutado pelo nível inferencial.

Mas esses processos de simulação não são simplesmente a mobilização de informações estocadas na memória de longo prazo. A simulação mobiliza as informações tais como são processadas pelo nosso aparato experiencial e cognitivo. Nesse sentido, nossas próprias capacidades são simuladas, ou, noutros termos, são ativadas de um modo off-line. ${ }^{15}$ Isso é importante para que as simulações sejam pertinentes ao tipo de interação que o agente pretende realizar diante do fenômeno. Nessa perspectiva, a conceituação envolve um conjunto de simulações de diferentes subsistemas em conexões recíprocas.

14 Há muitos casos já bem documentados pela literatura empírica que mostram que a atividade de capacidades cognitivas dependem de capacidades sensório-motoras, por exemplo, calcular e imaginar. Sobre isso, PEZZULO et al. (2013).

15 A ativ ação "off-line" significa quetais simulações nem sempre levam a comportamentos. A demais, que o agente não precisa estar em uma situação perceptiva relevante para que haja simulação. 
Vejamos o seguinte exemplo: após várias experiências perceptivas com um dado fenômeno, a informação visual acerca da sua aparência, a informação auditiva acerca do som por ele produzido, bem como as informações motoras acerca de como interagir com ele, estão integradas mediante a interconexão dos processos de simulação. Essa integração permite mobilizar o conceito em um contexto inferencial, como também realizar predições sobre o comportamento do fenômeno em questão. Simulações permitem, por conseguinte, não somente reconhecer e interagir com o objeto, mas também produzir inferências e predições sobre as instâncias de uma determinada categoria. Aqui temos simulações de nível superior, pelas quais o conteúdo informacional se coloca no domínio cognitivo. Esses processos inferenciais não dependem da posse explícita de princípios da lógica, mas sim de um ajuste às situações nas quais o agente está engajado. Tal ajuste, por sua vez, envolve simulações do conteúdo sensório-motor e afetivo. Note-se uma vez mais que, mesmo nesse nível superior, o conteúdo conceitual que figura nas estruturas cognitivas é modulado por capacidades sensório-motoras e emocionais básicas.

Tendo em vista esse quadro geral da teoria da cognição ancorada, podemos agora mostrar que o caráter reflexivo da crença teísta não anula a sua aderência. Vale a pena retomarmos a tese de que, a rigor, não temos uma percepção direta de Deus. A crença teísta surge como uma reflexão acerca do conteúdo da experiência. Vejamos agora como descrever esse processo a partir da cognição ancorada. Como vimos, a experiência perceptiva de vastidão, dada a sua magnitude, engaja diferentes canais sensoriais, bem como desperta emoções de enlevo, gratidão, admiração, entre outras. Essa magnitude que se manifesta nesse tipo de experiência não conceitual constitui o conteúdo dos processos de simulação. Esses processos, por sua vez, são caracterizados por uma reconstrução, no mais das vezes implícita, desses estados perceptivos e emocionais.

Nossa hipótese explicativa é que esse conteúdo que resulta da interconexão entre os processos de simulação é conceituado como manifestação de grandeza e onipotência divina. Nesse caso, a crença em um ser onipotente decorre de uma acomodação cognitiva de um conteúdo não-conceitual. A crença teísta é o resultado 
dos processos de simulação de baixo nível, acerca do conteúdo não-conceitual da experiência de vastidão, e de alto nível, que é constituído pela posse de outros tantos conceitos e por processos inferenciais. Por esse motivo, a crença teísta não é uma crença básica. Mas, em que pese o seu caráter reflexivo, não se trata de uma interpretação emocionalmente neutra de um determinado tipo de experiência. Pelo contrário, a crença teísta carrega os aspectos constitutivos da experiência de vastidão.

Por certo, os processos simulativos dessa experiência, ativados em um modo off-line, têm menos riqueza fenomenológica do que uma situação perceptiva. Mesmo assim, trata-se de um processo interpretativo permeado pelos traços de aderência presentes na experiência de vastidão. Do ponto de vista de uma teoria integrativa como a teoria da cognição ancorada, capacidades cognitivas de ordem superior não flutuam para além de capacidades presentes na experiência. Por essa razão, dependendo do tipo de experiência à qual estão direcionadas, crenças reflexivas, tais como a crença teísta, podem, sim, ter caráter evocativo e transformador.

Por fim, os diferentes processos de simulação que culminam na crença teísta têm impacto profundo na vida das pessoas, mesmo que elas não estejam em uma situação perceptiva relevante. Com base nisso podemos entender que a mera evocação de uma crença teísta, caso em que há simulação explícita, pode encorajar, aliviar ou mesmo enlevar. A crença teísta decorre de uma atividade cognitiva de ordem superior, que resulta desses processos de simulação de um aparato sensórioafetivo fortemente impactado por uma experiência de vastidão. É justamente na crença teísta que esse conteúdo não-conceitual da experiência é plenamente acomodado. Por essa razão, o caráter reflexivo da crença teísta não enfraquece a sua aderência.

\section{CONSIDERAÇÕES FINAIS}

Uma motivação para a defesa de que a crença teísta é uma crença básica, adquirida independentemente das capacidades reflexivas do agente, é o seu caráter 
aderente. Pode parecer que colocaríamos a perder essa aderência própria da crença teísta se a concebêssemos como uma crença reflexiva. No entanto, como vimos, existem problemas importantes que se colocam para a tentativa de se compreender a crença teísta como crença básica. Nossa proposta consistiu em apresentar uma alternativa para a defesa do caráter reflexivo da crença teísta. Como vimos, o que pode colocar em questão a concepção reflexiva da crença teísta é o argumento de que capacidades cognitivas de ordem superior não são aderentes. Procuramos, entretanto, assumir uma postura crítica em relação a esse argumento, que de resto termina por cindir capacidades cognitivas de capacidades sensoriais, afetivas e motoras. A partir do marco teórico da cognição ancorada, as capacidades cognitivas de ordem superior são indissociáveis de capacidades sensoriais, afetivas e motoras. Esse marco teórico pode ser útil para explicar um caso de acomodação do conteúdo não-conceitual presente na experiência de vastidão. Mediante a simulação de baixo nível, o conteúdo dessa experiência é integrado; mediante a simulação de alto nível, esse conteúdo é mobilizado em um contexto inferencial. Finalmente, a crença teísta é resultado desse processo inferencial.

\section{REFERÊNCIAS}

BARSALOU, Lawrence. Grounded Cognition. The Annual Review of Psychology. n. 59: p.617-645, 2008.

BARSALOU, Lawrence. Simulation, situated conceptualization, and prediction. Philosophical Transactions, n. 364, p. 1281-1289, 2009. DAVIDSON, Donald. Three Varieties of Knowledge. In. Subjective, Intersubjective, Objective. New York, 2001.

DRETSKE, Fred. Knowledge and Flow of Information. Palo Alto: CSLI Publications, 1999

EVANS, Gareth. The Varieties of Reference. Clarendon. 1982.

GOLDMAN, Alvin. Discrimination and Perceptual Knowledge. The Journal of Philosophy, 73, p. 771-791, 1976.

KELTNER, Dacher. HAIDT, Jonathan. Approaching awe, a moral, spiritual, and aesthetic emotion, Cognition and Emotion, 17 (2), p. 297-314. 2003. 
LEOPOLD, David. Primary visual cortex, awareness and blindsight. Annual Review Neuroscience. 35, p. 91-109, 2012.

McCAULEY, Robert. Why religion is natural and science is not. Oxford Press, 2011.

McDOWELL, John. Mind and World. Harvard Press, 1996.

McDOWELL, John. Conceptual Capacities in Perception. In. Kreativitat. Felix Verlag, 2006.

MILLIKAN, Ruth. Language, Thought and Others Biological Categories. Mit Press, 1984.

PEZZULO, Giovanni; BARSALOU, Lawrence; CANGELOSI, Angelo; FISCHER, Martin; McRAE, Ken; SPIVEY, Michel. Computational Grounded Cognition: a new alliance between grounded cognition and computational modeling. Frontiers in Psychology, p. 1-11, 2013.

PIAGET, Jean. INHELDER, Bärbel. The psychology of the child. New York: Basic Books. 1966.

PLANTINGA, Alvin. Warranted Christian Belief. New York: Oxford University Press, 2000.

PORTUGAL, Agnaldo. Plantinga and the Bayesian Justification of Beliefs. Veritas (Porto Alegre. Impresso), v. 57, p. 15-25, 2012.

RAMSEY, Frank. Foundations - Essays in Philosophy, Logic, Mathematics and Economics. London: Routledge and Kegan Paul. 1978.

SHAPIRO, Lawrence. Embodied Cognition. Taylor e Francis. 2011.

SHIOTA, Michelle; KELTNER, Dacher; MOSSMAN, Amanda. The nature of awe: Elicitors, appraisals, and effects on self-concept. Cognition and Emotion, 21 (5), p. 944-963, 2007. 